\title{
Assessing pollution-related effects of oil spills from ships in the Chinese Bohai Sea
}

\author{
Xin Liu ${ }^{\text {a,b,c,* }}$, Mingxian Guo ${ }^{\mathrm{d}}$, Yebao Wang a,b,c,e ${ }^{\text {, Xiang Yu }}{ }^{\text {a,b,c,e }}$, Jie Guo ${ }^{\text {a,b,c }}$, Cheng Tang ${ }^{\text {a,b,c }}$, Xiaoke Hu ${ }^{\text {, }}$ \\ Chuanyuan Wang ${ }^{\text {a,b,c }}$, Baoquan Li $^{\text {a,b,c }}$ \\ a Key Laboratory of Coastal Zone Environmental Processes, CAS, Yantai 264003, PR China \\ b Shandong Provincial Key Laboratory of Coastal Zone Environmental Processes, Yantai 264003, PR China \\ c Yantai Institute of Coastal Zone Research, Chinese Academy of Sciences, Yantai 264003, PR China \\ ' Sun Tat-Sen University, Guangzhou 510275, PR China \\ e University of Chinese Academy of Sciences, Beijing 100049, PR China
}

\section{A R T I C L E I N F O}

\section{Article history:}

Received 18 December 2015

Received in revised form 13 June 2016

Accepted 14 June 2016

Available online 26 June 2016

\section{Keywords:}

Bohai Sea

China

Contingency management oil spill

Statistical analysis

Trajectory simulation

\begin{abstract}
A B S T R A C T
An analysis of the effects of potential oil spills will provide data in support of decisions related to improving the response to oil spills and its emergency management. We selected the Chinese Bohai Sea, especially the Bohai Strait, as our investigation region to provide an assessment of the effects of pollution from ship-related oil spills on adjacent coastal zones. Ship-related accidents are one of the major factors causing potential oil spills in this area. A three dimensional oil transport and transformation model was developed using the Estuary, Coastal, and Ocean Model. This proposed model was run 90 times and each run lasted for 15 days to simulate the spread and weathering processes of oil for each of four potential spill sites, which represented potential sites of ship collisions along heavy traffic lanes in the Bohai Sea. Ten neighboring coastal areas were also considered as target zones that potentially could receive pollutants once oil spilled in the study areas. The statistical simulations showed that spills in winter were much worse than those in summer; they resulted in very negative effects on several specific target zones coded Z7, Z8, Z9, and Z10 in this paper. In addition, sites S3 (near the Penglai city) and S4 (near the Yantai city) were the two most at-risk sites with a significantly high probability of pollution if spills occurred nearby during winter. The results thus provided practical guidelines for local oil spill prevention, as well as an emergency preparedness and response program.
\end{abstract}

@ 2016 Elsevier Ltd. All rights reserved.

\section{Introduction}

The implementation of various laws and regulations has dramatically reduced oil spills at sea worldwide since the 1980s. However, large oil spills continue to occur irregularly. For example, the Deepwater Horizon explosion on April 20, 2010 resulted in oil spilling into the Gulf of Mexico for three months. This disaster is the world's largest accidental marine oil accident on record. An estimated 4.9 million barrels of crude oil were released before the wellhead was capped (Hoch, 2010). In late November 2010, $510 \mathrm{~km}$ shoreline in Louisiana was covered with gobs of crude (TELEGRAPH, 2010). The spill caused extensive damage to marine and wildlife habitats and to the fishing and tourism industries in the Gulf.

The environmental management community has an increasing awareness of the need to minimize the effects of pollution on vulnerable coastal areas once oil spills occur at sea (Vandermeulen and Ross, 1995; Michel et al., 2002; Abascal et al., 2010). Hence, prior to an oil spill, conducting an assessment of the potential effects of pollution can provide

\footnotetext{
* Corresponding author at: Key Laboratory of Coastal Zone Environmental Processes, CAS, Yantai 264003, PR China.

E-mail address: xliu@yic.ac.cn (X. Liu).
}

a useful tool to allow land managers to identify coastal areas in need of greater levels of protection and improved management. Many international references provide information related to simulations of the fate of spilled oil (Spaulding et al., 1994; Varlamov et al., 1999; Elliott, 2004; Wang et al., 2008); these have been developed in the context of numerical ocean modeling (Oey et al., 2005). For example, scientific literature includes the studies of many oceanographers who have investigated an oil spill simulation based on a single case. These studies employed many kinds of models including Princeton Ocean Model, the Estuary, Coastal and Ocean Model (ECOM), the Finite Volume Community Ocean Model, the Hybrid Coordinate Ocean Model, the Regional Ocean Modeling System, and the General NOAA Oil Modeling Environment (Xu et al., 2012; Jin and Wang, 2004; Mariano et al., 2011; Marta-Almeida et al., 2013; Deng et al., 2013a). These models may or may not take into account the weathering processes of oil in sea water. However, to date few studies have presented a comprehensive image of effects of pollution based on numerical modeling using multiple hypothetical oil spills. French-McCay et al. (2004) evaluated the potential bio-economic effects of hypothetical oil spill scenarios in San Francisco Bay based on OILMAP modeling, using this three-dimensional oil spill model. Using Lagrangian passive tracer transport simulations Chrastansky and Callies (2009) analyzed the effects 
of chronic oil pollution along the German North Sea coast. Guillen et al. (2004) used the Oil Spill Risk Analysis model to identify areas at risk from oil spills in the Gulf of Mexico. Deng et al. (2013b) conducted sixteen simulation experiments for four potential oil spills linked to offshore oil drilling fields in the Chinese Bohai Sea. However, most of the studies mentioned above have been completed using commercial software such as OILMAP, Oil Spill Contingency and Response, the General NOAA Oil Modeling Environment, and Oil Spill Risk Analysis Model instead of open-use resources. They exhibited a wide range of complexity. Many researchers cannot directly use them for their own regional simulations because of their high cost and inflexibility. To remedy this situation, this paper suggested a novel approach by coupling statistical data and oil fate simulations developed using ECOM. Researchers used open source FORTRAN code to develop ECOM and it can be downloaded at no cost through the HydroQual website (HydroQual, 2015). This paper differentiates itself from previous studies (Wang et al., 2005, 2008; Deng et al., 2013a) on oil spills specifically in the Bohai Sea; rather than involving a single case simulation, it takes a comprehensive overview of oil spill risk based on a multiple of simulations with various uncertainties. Furthermore, the paper is dedicated to oil spills linked to ship accidents, which could complement a study related to offshore oil drilling field spills in the Chinese Bohai Sea (Deng et al., 2013b).

In the present paper we modeled a set of hypothetical scenarios for ship related oil spills in the Bohai Sea using ECOM. A large sample of simulations (i.e., 360 runs) focusing on four potential ship accident sites was performed with the most important driving forces related to realistic weather conditions and tidal currents. We compared the exposure of coastal areas to oil spills and further determined coastal areas that are at a potentially high risk of experiencing oil spills. Based on the effects to coastal areas simulated in the different hypothetical spill scenarios, we finally summarized the magnitude of risk for those spill sites. This study provides insight into both seasonal and spatial patterns of ship related oil pollution in the Bohai Sea, China.

In this paper, Section 2.1 presents a general overview of the study area and recent records of oil spills in this specific area. Sections 2.22.5 described the Lagrangian oil spill model and the development of simulations with details of the model inputs. Section 3 discusses two aspects of the outcomes of oil spill simulations: 1 ) various coastal locations affected by potentially spilled oil; and 2) risk ranking of potential spill sites. Finally, Section 4 gives major findings. The goal of this paper is to answer important planning questions such as: "What areas may experience oil slicks?" and "Which potential spill sites are at risk of causing damage to surrounding coasts given the amount of oil spilled?"

\section{Methods}

\subsection{Study area}

The Bohai Sea, located in northeastern China, forms a " $\mathrm{C}$ " shaped and semi-enclosed shallow sea (Fig. 1) with an average and maximal depth of $18 \mathrm{~m}$ and $80 \mathrm{~m}$, respectively (Sündermann and Feng, 2004). Generally, the Bohai Sea can be divided into five major regions including the Liaodong, Bohai, Laizhou bays, the central area and the Bohai Strait (Fig. 1b). The Bohai Sea has been one of the most productive offshore oil-producing areas in China since the 1980s. However, rapid developments related to oil exploitation and transportation have resulted in frequent oil spills in this area recently. Based on statistics, three major oil spills occurred in the Bohai Sea from 2005 to 2011. For example, the Portuguese oil tanker "Arteaga" became stranded 4.3 nautical miles out of Dalian Harbor on 3 April 2005. This accident caused hundreds of tons of heavy oil to spill into the sea. An explosion in an oil pipeline close to the Dalian Harbor caused 1500 tons of heavy oil to spill into the Bohai Sea on 16 July 2010. According to estimates, almost $870 \mathrm{~km}^{2}$ of sea water has been polluted by the spill and over 1000 ships have been involved in the cleanup (Liu and Zhu, 2014). On 4 June 2011, oil was observed on the surface of coastal waters near platform $B\left(38^{\circ} \mathrm{N}, 120.0^{\circ} \mathrm{E}\right)$, in the Penglai 19-3 nearshore oil drilling field operated by ConocoPhillips China Inc. (COPC, 2012). By June 17, 2011, $840 \mathrm{~km}^{2}$ of clean coastal waters, an area 1.2 times the size of Singapore, had become polluted.

The Bohai Sea is very vulnerable to any size of an oil spill, because it is important not only economically but ecologically. It provides wetlands, tidal flats, and estuaries of moderate salinity and temperature that in turn provide habitat for a wide variety of birds, fish, mussels and other species (Zhou et al., 2007; Ning et al., 2010). Oil spill contingency management for the Bohai Sea is, thus, an ongoing concern in the context of integrated coastal zone management among the national and local governments as well as with the public. A basic part of the oil spill contingency management is to determine which coastal locations would be most seriously damaged by an oil spill so that they may receive priority protection (Gundlach and Hayes, 1978). Therefore, assessment of the effects of potential oil spills and of the coasts that are likely to become polluted by oil is needed (Abascal et al., 2010).

This paper is focused on ship related oil spills along busy traffic lines in the Bohai Sea. The Bohai Strait is the only passage connecting the inner Bohai Sea with the open ocean (i.e., the Yellow Sea). Two eastwest lines represented the busiest shipping traffic lanes because all vessels either entering or leaving the Bohai Sea must follow these two
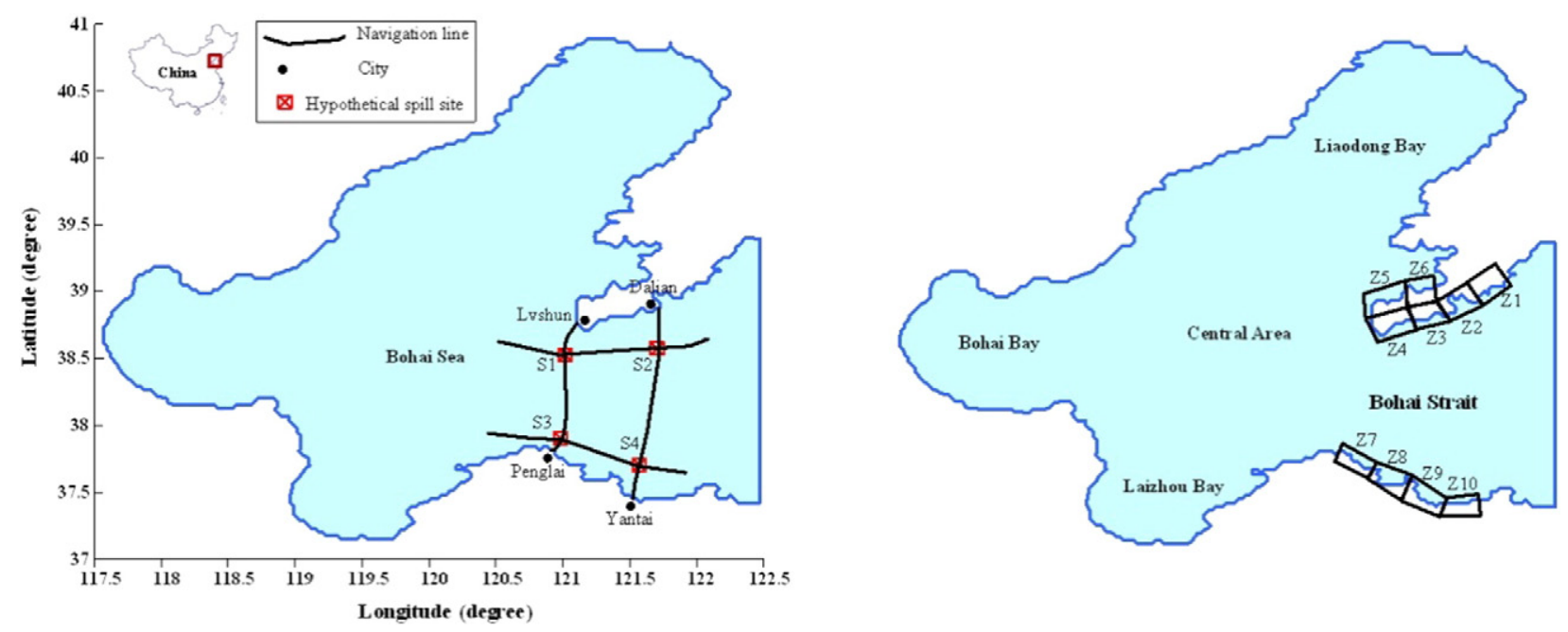

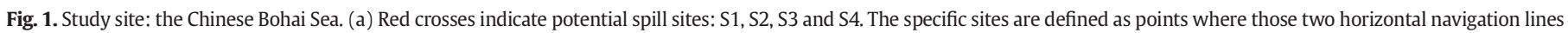
meet those two vertical navigation lines. (b) Z1-Z10 indicate target regions along the Bohai Strait discussed here. 
shipping lanes (Fig. 1a). Similarly, two north-south lines connect two pairs of coastal cities: Penglai/Lvshun and Yantai/Dalian along the coast of the Bohai Strait (Fig. 1a). Ferries regularly and daily operate along these two north-south shipping lanes in summer. The two eastwest shipping lanes meet the two north-south ones at four intersections which were defined as potential oil spill sites related to traffic in this paper (Fig. 1a).

\subsection{Lagrangian particle algorithm}

Oil spill simulation consisted of two major parts: hydrodynamic modeling and particle tracking. A hydrodynamic model for the Chinese Bohai Sea was fully developed using ECOM with various data for bathymetry, initial condition, open boundary and gridding. More details on ECOM can be found on the HydroQual website (HydroQual, 2015). To simulate the drift of oil slicks, a three dimensional oil transport model was then developed based on both hydrodynamics and a Lagrangian discrete particle algorithm. The simple weathering processes including spreading, stranding, evaporation and emulsion were also considered in the model. The movement of a large number of small oil particles of equal mass can be driven by the media such as sea water with the velocity components, the buoyancy velocity of oil particles and the turbulent fluctuations (Wang et al., 2008). Hence, the $X, Y$ and $Z$ coordinates of oil particles can be written using Eq. (2.1) following Wang et al. (2008):

$$
\left\{\begin{array}{l}
d X / d t=\vec{U}+U \\
d Y / d t=\vec{V}+V \\
d Z / d t=\vec{W}+W+u_{b}
\end{array}\right.
$$

where $\vec{U}(x, y, z, t), \vec{V}(x, y, z, t)$ and $\vec{W}(x, y, z, t)$ represented the drift velocity of oil particles caused by the combined forces of wind, current and waves, $U_{b}$ was the buoyancy velocity and $U(x, y, z, t), V(x, y, z, t)$ and $W(x, y, z, t)$ were the turbulent fluctuations of velocity of oil particles in the water column.

\subsection{Oil spill simulations}

To simulate the drift of hypothetical oil spills from various sites, a three dimensional oil transport model was developed based on ECOM that included a variety of processes such as spreading, stranding, evaporation and emulsion. By using the proposed oil spill transport and transformation model, a matrix of spill scenarios for four potential spill sites (S1, S2, S3, S4), thirty environmental conditions and three spill sizes (100, 500, and 1000 tons representing small, medium and large spills, respectively, for simplicity) were analyzed. For each potential site and each of the three spill size scenarios, thirty simulations were run with each run specifying a set of environmental conditions from a possible range of conditions. Liang et al. (2003) reported that summer and winter incorporate typical environmental conditions for the Bohai Sea. In summer, southern winds prevail and ferries frequently carry tourists across the Bohai Sea strait. In winter, strong northern winds blow and ships are sometimes at the mercy of adverse weather conditions. Therefore, oil spills caused by ship accidents are more likely to occur in these two extreme seasons: summer and winter. The proposed model simulated a total of 30 sets of widely variable conditions, fifteen sets of summer conditions (June, July, August from 2005 to 2009) together with another fifteen simulating winter conditions (January, February, December from 2005 to 2009). Namely, 15 summer conditions include June/2005, July/2005, August/2005, June/2006, July/2006, August/2006, June/2007, July/2007, August/2007, June/2008, July/2008, August/2008, June/2009, July/2009, and August/2009 and 15 winter conditions include January/2005, February/2005, December/2005, January/2006, February/2006, December/2006, January/2007, February/ 2007, December/2007, January/2008, February/2008, December/2008,
January/2009, February/2009, and December/2009. In each of the model runs, simulated oil particles were driven by important environmental conditions such as tidal currents and wind. The tidal currents in the Bohai bay, the Liaodong bay and the Laizhou bay were all normally semi-diurnal tide with a period of $12-13 \mathrm{~h}$. It was reciprocating flow induced by tides in the middle of Bohai Sea (Liu et al., 2015). In terms of effects, the number of drifting particles that accumulatively reached the different target regions (Fig. 1b) by the end of a simulation was recorded in each of run. Each simulation lasted for 15 days. The model was truncated at day 15 , partly because evaporation, the most important weathering process that influences the reduction in volume of spilled oil, is normally limited to the first $48 \mathrm{~h}$ after the spill (Azevedo et al., 2014), and partly because the local half-life of petroleum hydrocarbons is approximately six days. Moreover, 15 days was long enough to allow the oil spilled in the Bohai Sea Strait to spread and eventually to become stranded on the beach during the pre-test simulations.

\subsection{Model inputs}

The digital coastal line was extracted from the National Geophysical Data Center (NOAA, 2010) and bathymetry data (Fig. 2) was obtained based on in-situ measurements. To develop a three dimensional model, rectilinear grids were generated horizontally to cover the entire domain ranging from 117.5 to $122.5^{\circ}$ longitude and from 37 to $41^{\circ}$ latitude in the local coordinate system. The grid cell size was $1.67^{\prime}$ by 1.67 ' for both longitude and latitude (i.e., nearly $3.09 \mathrm{~km} \times 3.09 \mathrm{~km}$ ). The mesh covered 180 cells $(x$ direction) $\times 144$ cells $(y$ direction). Ten layers were designated vertically. All wind data were downloaded from QuikScat with a resolution of $0.5^{\circ}$ by $0.5^{\circ}$ (2009). Using the Lagrangian algorithm, simulated surface oil particles were drifted by both wind and tidal currents. In this study model the region was spanned between $37^{\circ} \mathrm{N}$ and $41^{\circ} \mathrm{N}$ and between $117.5^{\circ} \mathrm{E}$ and $122.5^{\circ} \mathrm{E}$ with an open boundary defined along the right most vertical line at $122.5^{\circ} \mathrm{E}$, which was consistent with HAMburg Shelf Ocean Model (HAMSOM), a well established model in the Bohai Sea (Hainbucher et al., 2004). The range is larger than the Bohai Sea boundary and the hypothetical spill sites were not very close to the open boundary (Mao et al., 2008). Two hydrology stations are located at Dachangshan and Jiming islands along the open boundary line (Fig. 2). Amplitudes and phases for four major harmonic constants (M2, S2, K1, and O1) were obtained from these two local stations as described in publications (Wei et al., 2004). However, only two diurnal tidal components (O1 and K1) may be not enough in showing the variation of the spring-neap cycle. The model should be improved in the future (Dai et al., 2015). The initial conditions for open boundary conditions were then interpolated to drive the simulated tide. The instantaneous water level and current speed can be calculated in the model. Surface water temperature and salinity were varied by the month of the oil spill simulation, based on an average of monthly mean surface water temperature and salinity, respectively, for the central Bohai Sea (Mao et al., 2008). The flow in the Bohai Sea is almost completely tidal induced and for the present analysis, the density driven flows were not considered (Wei et al., 2004; He et al., 2004). Four potential spill sites: S1, S2, S3, and S4 were modeled (Fig. 1a). Simulated oil was transported assuming neither removal of mass by cleanup nor the application of dispersants. While considering the decay rate of oil and time consumption of computation, the duration of the simulation was limited to 15 days. Table 1 summarizes the details of input parameters for all scenarios. The oil tracking model provided trajectory data of hypothetical oil spills over many months, which can be used for additional estimation of the relative distribution of oil from spills at the four specific potential sites.

\subsection{Effect analysis and risk evaluation}

Target zones exposed to oil spills were analyzed in each run to assess the effects of oil spills. This consequence was measured as the number 


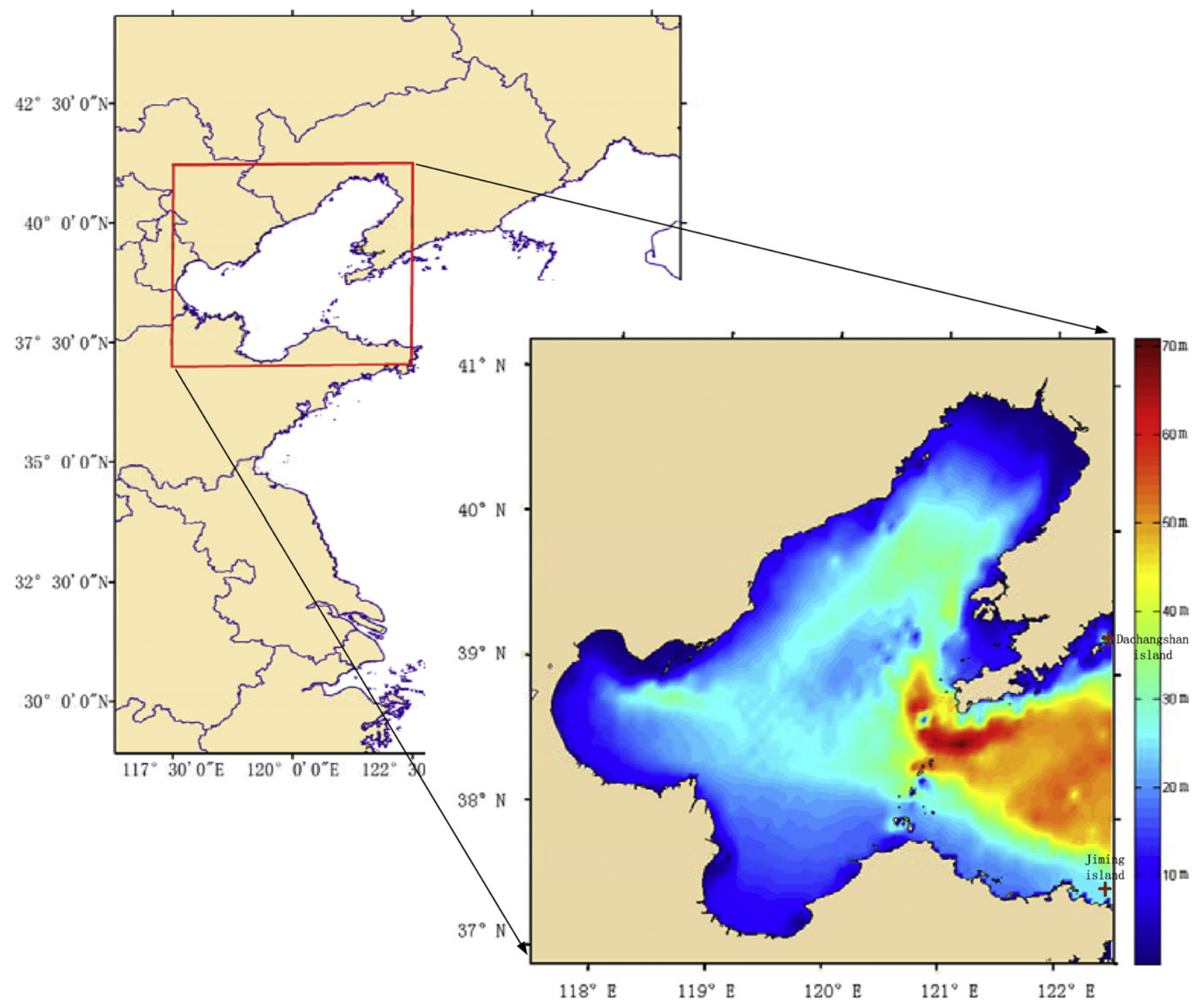

Fig. 2. Bathymetry data including water depth $(\mathrm{m})$ in the Bohai Sea, China. Red crosses indicate locations of two local hydrology stations providing data related to tidal constituents.

of oil particles reaching the target zones with a comparison to the total number of oil particles released (\%). We assumed that if more oil particles reached a specific target zone, the effects of oil on these target zones were much greater. Hence, a new parameter associated with the pollution effect $(P)$ was defined using Eq. (2.2):

$p_{n}^{m}={ }^{s_{n}^{m}} /_{t^{m}} ; \quad(n=Z 1, Z 2, \ldots, Z 10 ; m=1,2,3, \ldots, 360)$

where $m=[1,2, \ldots, 360], p_{n}^{m}$ represents the pollution effects on target zone $n$ in the $m$ th simulation; $\mathrm{s}_{n}^{m}$ and $t^{m}$ were the number of oil particles reaching the target zone and the total number of oil particles released in the $m$ th simulation, respectively. The maximal value of the pollution effect to target zone $n$ was described as $R_{n}$ using Eq. (2.3):

$R_{n}=\max \left(p_{n}^{m}\right) ; \quad\left(p_{n}^{m}=p_{n}^{1}, p_{n}^{2}, \ldots, p_{n}^{360}\right)$

Table 2 shows the classification of the seven grades based on the value of $R_{n}$. This criterion was used to delineate the maximal percentage of oil particles received by each target zone.

To determine the contribution of a specific spill site to all the target zones, another parameter related to the risk of an spill site was introduced here and was calculated using Eq. (2.4):

risk $^{i}={ }^{100 \% * \sum_{k=1}^{90} \sum_{n=\mathrm{Z} 1}^{\mathrm{Z10}} S_{n}^{(i-1) * 90+k}} / \sum_{k=1}^{90} t^{(i-1) * 90+k}$

where risk ${ }^{i}$ was the risk of a spill at site $i$ and $i$ was referred to as 1,2, 3, and 4 for spill sites S1,S2, S3, and S4, respectively. As defined previously, in the particular $((i-1) \times 90+k)$ th simulation, $s_{n}^{m}$ and $t^{m}$ refer to the number of oil particles reaching the target zone $n$ and the total number of oil particles released, respectively. A total of 360 simulations were conducted because each of four spill sites involved 90 simulations ( $360=4$ spill sites $\times 3$ spill sizes $\times 30$ wind conditions). 30 wind conditions were collected from the specific months of January, February, June, July, August and December at the Year 2005, Year 2006, Year 2007, Year 2008 and Year 2009. All simulations were numbered with respect to their spill sites. For example, the first and second 90 hypothetical simulations corresponded to oil spills in sites S1 and S2, respectively, so that simulations $271-360$ referred to oil spills occurring in site S4. Five levels of risk were defined (Table 3). 
Table 1

Inputs to simulation models.

\begin{tabular}{|c|c|c|}
\hline Name & Description & Value(s) \\
\hline Oil type & Heavy oil released & Statfjord \\
\hline Oil density & Density of oil released & $\begin{array}{l}0.832 \mathrm{~g} / \mathrm{cm}^{3} \\
\mathrm{~S} 1: 121.033^{\circ} \mathrm{E} ; 38.583^{\circ} \mathrm{N}\end{array}$ \\
\hline Spill site & $\begin{array}{l}\text { Latitude and longitude of the } \\
\text { release }\end{array}$ & $\begin{array}{l}\text { S2: } 121.710^{\circ} \mathrm{E} ; 38.653^{\circ} \mathrm{N} \\
\text { S3: } 120.964^{\circ} \mathrm{E} ; 37.923^{\circ} \mathrm{N} \\
\text { S4: } 121.510^{\circ} \mathrm{E} ; 37.741^{\circ} \mathrm{N}\end{array}$ \\
\hline Release depth & $\begin{array}{l}\text { Depth below the water surface } \\
\text { (m)for spill }\end{array}$ & 0 for surface launch \\
\hline Spill start & $\begin{array}{l}\text { Hours over which the release } \\
\text { occurs }\end{array}$ & $48 \mathrm{~h}$ \\
\hline Model time step & $\begin{array}{l}\text { Time step used for model } \\
\text { calculations }\end{array}$ & $180 \mathrm{~s}$ \\
\hline Model duration & Length of each model simulation & 15 days \\
\hline Number of runs & $\begin{array}{l}\text { Number of simulations to run in } \\
\text { each spill site }\end{array}$ & 90 \\
\hline Spill size & Oil amounts in ton per release & $\begin{array}{l}\text { Small spill: } 100 \text { tons } \\
\text { Medium spill: } 500 \text { tons } \\
\text { Large spill: } 1000 \text { tons }\end{array}$ \\
\hline $\begin{array}{l}\text { Number of oil } \\
\text { particles }\end{array}$ & Number of particles released & $\begin{array}{l}\text { Small spill: } 1000 \\
\text { Medium spill: } 5000 \\
\text { Large spill: } 10,000 \\
\text { Summer: June, July and } \\
\text { August; }\end{array}$ \\
\hline Wind data & $\begin{array}{l}\text { Wind records downloaded from } \\
\text { QuikScat }\end{array}$ & $\begin{array}{l}\text { Winter: January, February } \\
\text { and December } \\
\text { Year: } 2005,2006,2007,2008 \\
\text { and } 2009 \\
\text { (See Section } 2.3 \text { for details) }\end{array}$ \\
\hline
\end{tabular}

\section{Results and discussions}

\subsection{The fate of spilled oil}

Spilled oil was assumed to experience a range of physical and weathering processes such as spread and evaporation. Once the simulated oil reached a shoreline it was assumed to remain on shore. The weathering processes could not affect the number of oil particles but affect both the density and water contents of oil particles. As we had a focus on comparing coastal areas exposed to oil spills and determining coastal areas in high risk of oil pollution by a statistical analysis, results related to evaporations and emulsifications were not presented in the paper. Liu et al. (2015) discussed the weathering process in modeling trajectories of the Penglai 19-3 oil spill.

The movement of oil particles at the surface was driven mainly by the forces of wind and tidal currents in the Chinese Bohai Sea. In summer, the prevailing southeast wind had a speed below $4 \mathrm{~m} / \mathrm{s}$ to $6 \mathrm{~m} / \mathrm{s}$, while cold north winds blow over the Bohai Sea during winter. The mean monthly surface water temperature varied from $0{ }^{\circ} \mathrm{C}$ in February to $21^{\circ} \mathrm{C}$ in August in the Bohai Sea. MODIS satellite imagery with $250 \mathrm{~m}$ resolution (Su et al., 2013) revealed ice formed only along the very shallow coastal areas in the three bays: the Liaodong bay, the Bohai bay, and the Laizhou bay. Ice failed to cover both the central Bohai Sea and the Bohai Strait during winter. Accordingly, ice was not considered in the model for simplicity. In many cases, the location of an oil spill and the prevailing wind conditions were the most important factors that influenced the probability that a given coastal area would suffer from

Table 2

Classification of grades of effects.

\begin{tabular}{ll}
\hline Grades of effects & Definition \\
\hline Maximal & $R_{n} \geq=60 \%$ \\
Extremely high & $R_{n}=50-60 \%$ \\
Very high & $R_{n}=40-50 \%$ \\
High & $R_{n}=20-40 \%$ \\
Medium & $R_{n}=10-20 \%$ \\
Low & $R_{n}=1-10 \%$ \\
Minimal & $R_{n}<1 \%$ \\
\hline
\end{tabular}

Table 3

Levels of risk of an oil spill at a particular site in the Bohai Sea.

\begin{tabular}{ll}
\hline Levels of risk & Definition \\
\hline A great deal of risk & risk $^{i} \geq 45 \%$ \\
A fair amount of risk & risk $^{i}=20-44 \%$ \\
A small amount of risk & risk $^{i}=5-20 \%$ \\
Very little risk & risk $^{i}=1-5 \%$ \\
No risk & risk $^{i}<1 \%$ \\
\hline
\end{tabular}

pollution (Fig. 3). For instance, oil from S3 polluted coastal areas much more severely during January than during July (Fig. 3a-b). In contrast, spills at site S2 caused the coast next to Dalian to become more heavily contaminated with oil during July than that in January (Fig. 3c-d). The seasonal pattern of wind regime causes this because during winter the prevailing winds in the Bohai Sea generally come from either the north or northwest. Typical winds over the Bohai Strait tended to cause oil to drift toward the south and southeast. Meanwhile, in summer the wind came from the south-southwest, generating corresponding surface currents to spread oil to the north and northwest. The location of S3 was very close to the southern coast of the Bohai Strait (i.e., the city of Penglai) when compared with S2, which implied that spills from S3 threatened the southern target zones with a higher probability of contamination than spills from S2 during the winter (Fig. 3bd).

\subsection{Averaged pollution effects}

For each run and target zone, both quantities of oil particles received by the target zone and released by spill were compared. A ratio of these two quantities determined the effects of oil pollution (\%). Corresponding to hypothetical spills from four potential spill sites, the averaged effects of pollution on different target zones in each season, summer and winter, could be illustrated (Figs. 4 and 5, respectively). Figs. 4 and 5 can be used clearly to answer a question: "Which target zones were likely to be affected by spills from which site?" The averaged pollution effect in summer for each target zone was relatively low, varying from 0 to $7.2 \%$. A peak value of $43.94 \%$ occurred at $Z 7$, which was caused by spills at $\mathrm{S} 4$, followed by $42.4 \%$ of the effect value in target zone $\mathrm{Z} 4$ when hit by hypothetical spills from site S2. During the 15 day simulation in summer, spills at site S1 would have almost no effect on all target zones along the coast of the Bohai Strait and target zones Z5, Z9, and Z10 were never damaged by simulated oil from any potential sites (Fig. 4). According to averaged value of simulated effects in summer, pollution at target zones Z1, Z2, Z3 and Z4 was mainly the result of oil spills at site S2, while spills at both S3 and S4 contributed to pollution at target zones Z6, Z7, and Z8 (Fig. 4).

During simulated winter, oil from site 54 had a maximal effect on target zones Z8 and Z9 and was as high as 61\%, although the averaged effect ranged from 0 to $19.7 \%$ (Fig. 5). Statistics related to the effect results (Fig. 5) show that when compared with those at sites S3 and S4, spills at S1 and S2 would have almost no effect on all target zones and target zones Z1 to Z5 were relatively safe, because those zones would receive no harm of oil particles during the 15 days simulation period. Generally, target zones Z6-Z10 were damaged mainly by spills from sites S3 and S4 in winter.

\subsection{Grading of pollution effects}

To delineate the effects of pollution on a target zone intuitively and to easily transfer the findings of the present study to contingency management, seven grades of effects were used as briefly mentioned in Section 2.5. Based on statistics of multiple simulations, an overall view of potential pollution effects on target zones is presented spatially in two seasons: winter and summer (Fig. 6). No target zones were designated as either "fairly high effects" or "very high effects" in summer, 


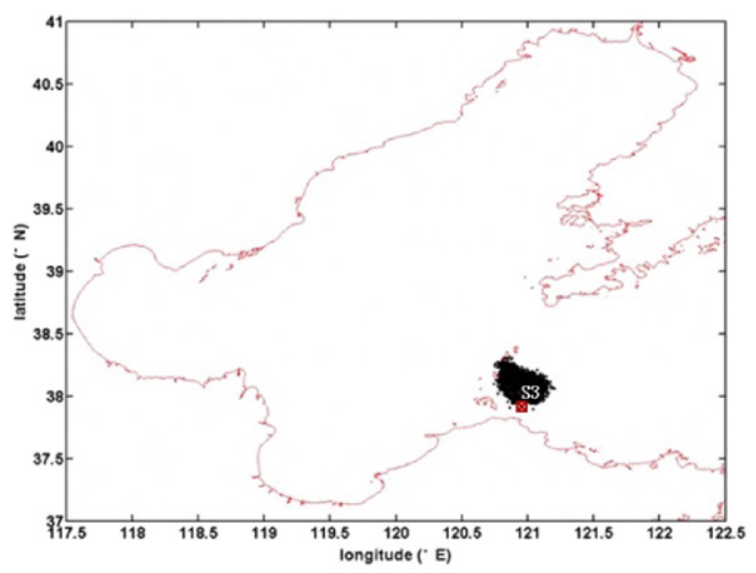

(a) Spill from S3 in July

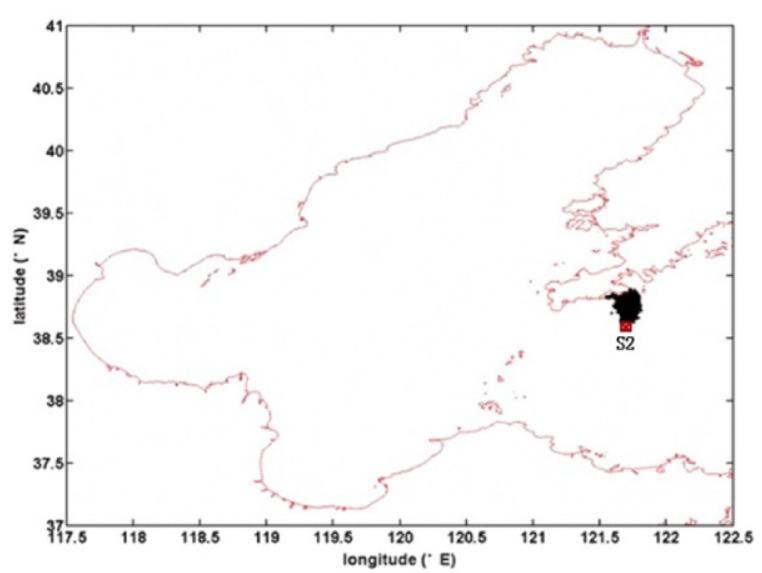

(c) Spill from S2 in July

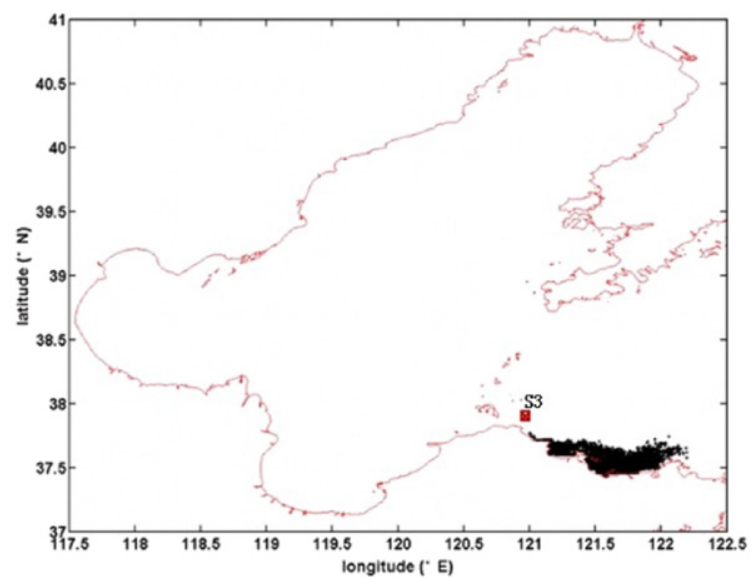

(b) Spill from S3 in January

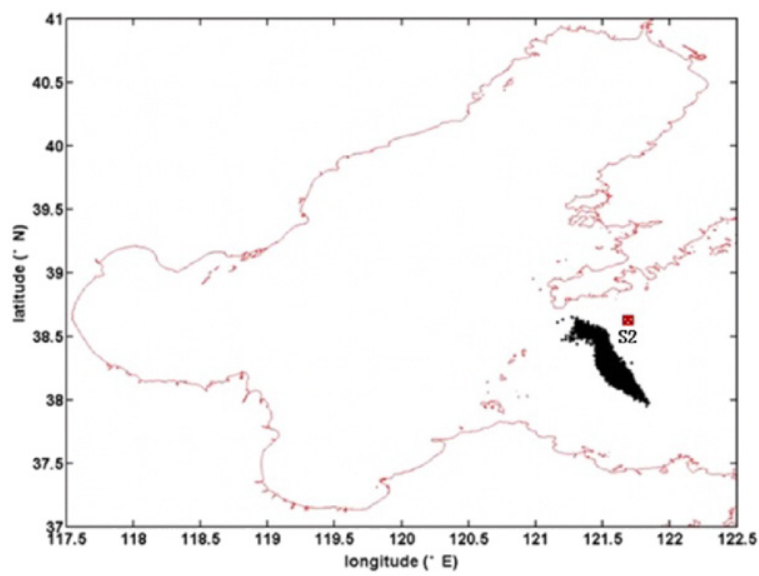

(d) Spill from S2 in January

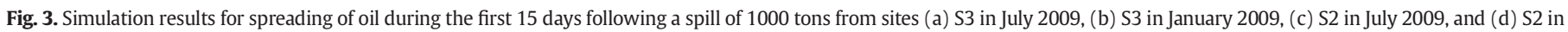
January 2009.

while in winter more oil drifted to several zones including Z7, Z8, Z9, and Z10. Specifically, Z8 and Z9 were ranked as experiencing "very high effects" and Z7 was ranked with "fairly high effects." Moreover, all zones along northern coastal area of the Bohai Strait were labeled as "fairly low effects" in winter, with the exception of Z6. Therefore, the northern coast where the cities of Lvshun and Dalian were located was much less likely to experience pollution from oil spills than was the southern coastline where Penglai and Yantai were located. That is, the typical northerly and northwesterly winds would drive spilled oil to flow toward the southern coastline of the Bohai Strait during winter.

\subsection{Risky spill sites}

Based on the effects to adjacent target zones, the risk of oil spilled from four potential spill sites was ranked to describe the risk of pollution in ten target zones. Five levels of risk were defined (Section 2.5). In summer, site S2 would experience "a little bit risk" (Fig. 7). This implies that spills at site $S 2$ would only cause a small amount of pollution to adjacent target zones. Both sites S3 and S4 were identified as experiencing "very little risk" followed by S1 with "no risk" (Fig. 7). Note that during winter, S3 was the most risky and critical site among four potential sites having "a great deal of risk." That is, spills at site S3 would result in large scale of pollution on nearby target zones. Following S3, site S4 would experience a "fair amount of risk." In both summer and winter, S1 was considered as a "no risk" site, which implies that spills at S1 would not cause pollution to surrounding target zones. Winter was considered the most critical season when compared to summer based on this type of seasonal comparisons. This finding was consistent with findings in Section 3.1. If oil was spilled at S3 or S4, particularly in winter rather than in summer, a great amount would be swept into the target zones. Under these conditions, corresponding combat/cleanup and environmental damage costs would increase significantly after a real spill.

\section{Conclusions}

For traffic-related oil spills in the Chinese Bohai Sea, the paper presents a statistical analysis of the effects of oil spills based on simulations. Simulations of oil fates including transportation and transformation were developed based on Lagrangian particle tracking theory by using ECOM. A total of 360 hypothetical simulations were done for four potential sites. Each run simulated 15 days to compute the relative percentage of oil particles reaching specific target zones. Prior to a real oil spill, a combination of model simulations and statistics was useful to qualify and quantify the potential effects of pollution on target zones exposed to oil. Moreover, particular spill sites with a high risk of polluting adjacent target zones have been determined by ranking the effects of spills from those sites. In summary, the major findings were as follows: 


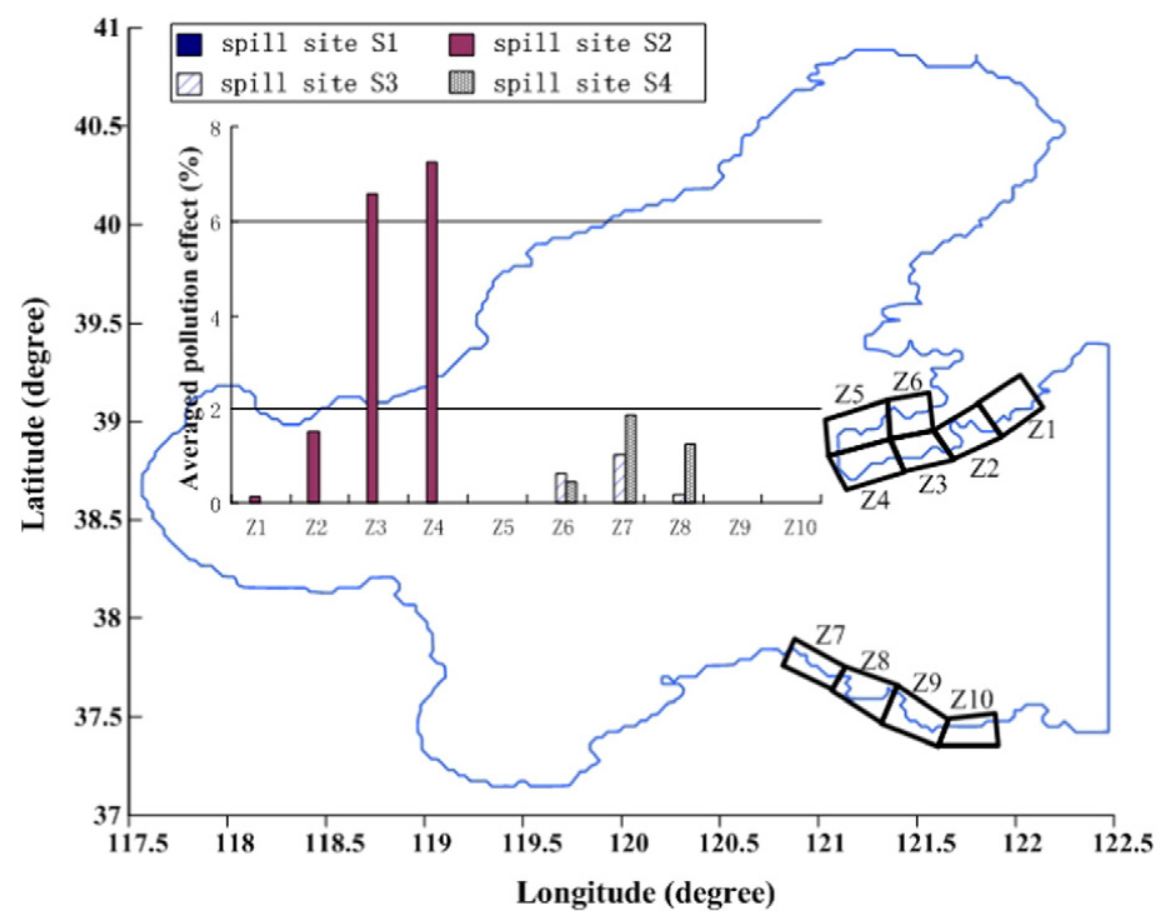

Fig. 4. Average effects of oil spills from four different spill sites on target zones Z1-Z10 in summer in the Bohai Sea.

1) Spills in winter were more critical than those in summer and more likely to threaten target zones along the Chinese Bohai Strait;

2) Without an appropriate response to oil spills, up to $61 \%$ of oil particles released at specific spill sites could reach the target zones within 15 days or less after a spill in winter;

3) Spills at site S1 near the city of Penglai would be very unlikely to cause damage to all target zones during both specific time periods analyzed here, both winter and summer and by extrapolation, all year long;
4) In winter, the integral southern part of coastal area of the Bohai Strait, including sites Z7-Z10, were identified as potential high effect zones, in which pollution would be expected to be very extensive and concentrated. In contrast, all the northern coastal areas of the Bohai Strait, with the exception of Z6 (i.e., zones from Z1-Z5) received fairly low effects from oil spilled during winter. Compared with summer, managers should pay more attention to preventing oil spills in winter that would affect the target zones and prepare for any cleanup in advance.

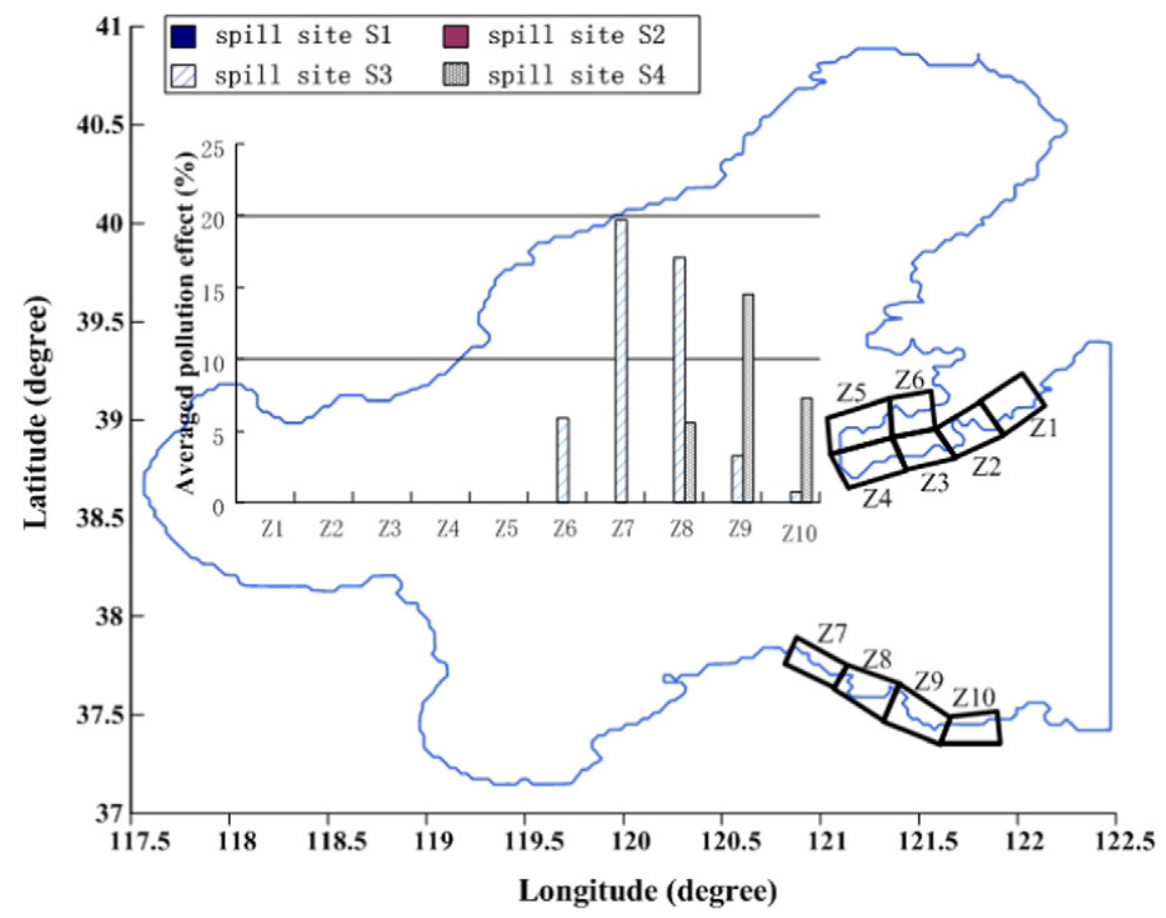

Fig. 5. Average effects of oil spills from four different spill sites on target zones Z1-Z10 in winter in the Bohai Sea. 


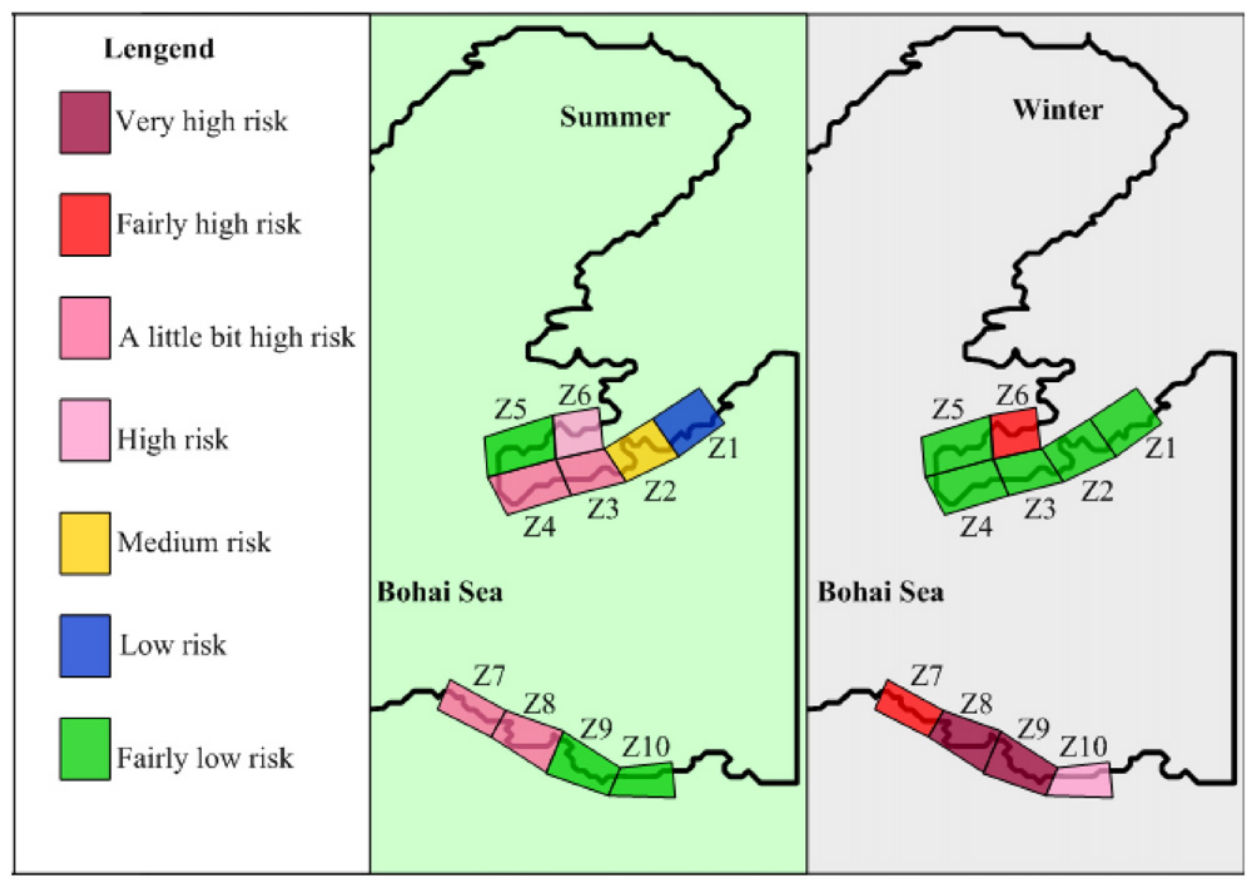

(a)

(b)

Fig. 6. Grade pollution effects in target zones $\mathrm{Z1}$ to $\mathrm{Z10}$ in (a) summer and (b) winter based on multiple simulations.

5) S3 followed by S4 were the highest risk spill sites among the four potential spill locations; approximately $46.6 \%$ of the simulated oil particles could reach specific target zones, affecting the coast along the Chinese Bohai Strait in winter time.

Further, the coupled approach presented in this paper extends the currently available ECOM oil spill simulations. These findings will facilitate a wide application of a similar methodology and similar studies related to spill events with negative environmental effects from oil tankers, oil pipelines or from oil drilling platforms. For example, we have used this proposed model for simulation of the recent Penglai 19-3 oil spill that resulted from offshore drilling in the Bohai Sea to develop an emergency response plan.

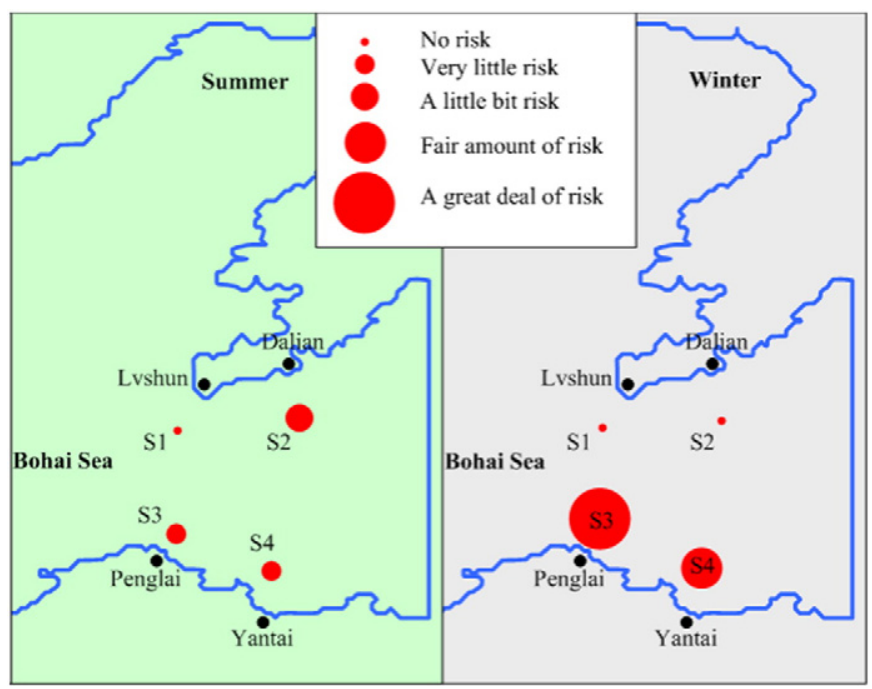

Fig. 7. Identification of high risk spill sites in the Bohai Sea. During summer, risk could be ranked as $\mathrm{S} 2>\mathrm{S} 3=\mathrm{S} 4>\mathrm{S} 1$; in winter risk was ranked as $\mathrm{S} 3>\mathrm{S} 4>\mathrm{S} 2=\mathrm{S} 1$.

\section{Acknowledgments}

The authors thank Dr. Yang Dezhou from the Qingdao Ocean Institute, Chinese Academy of Sciences for data sharing. This work is jointly supported by the funds numbered with NSFC41371483 and KZZD-EW14 from the Key Research Program of the Chinese Academy of Sciences.

\section{References}

Abascal, A.J., Castanedo, S., Medina, R., Liste, M., 2010. Analysis of the reliability of a statistical oil spill response model. Mar. Pollut. Bull. 60, 2099-2110.

Azevedo, A., Oliveira, A., Fortunato, A.B., Zhang, J., Baptista, A.M., 2014. A cross-scale numerical modeling system for management support of oil spill accidents. Mar. Pollut. Bull. 80, 132-147.

Chrastansky, A., Callies, U., 2009. Model-based long-term reconstruction of weather-driven variations in chronic oil pollution along the German North Sea coast. Mar. Pollut. Bull. 58, 967-975.

COPC, 2012. http://www.conocophillips.com.cn/EN/Response/Pages/default.aspx.

Dai, A., Li, K., Ding, D., Li, Y., Liang, S., Li, Y., Su, Y., Wang, X., 2015. Total maximum allocated load calculation of nitrogen pollutants by linking a 3D biogeochemical-hydrodynamic model with a programming model in Bohai Sea. Cont. Shelf Res. 111, 197-210.

Deng, Z., Yu, T., Shi, S., Jin, J., Jiang, X., Kang, L., Zhang, F., Wang, W., 2013a. Numerical study of the oil spill trajectory in Bohai Sea, China. Mar. Geod. 36, 351-364.

Deng, Z., Yu, T., Jiang, X., Shi, S., Jin, J., Kang, L., Zhang, F., 2013b. Bohai Sea oil spill model: a numerical case study. Mar. Geophys. Res. 34, 115-125.

Elliott, A.J., 2004. A probabilistic description of the wind over Liverpool Bay with application to oil spill simulations. Estuar. Coast. Shelf Sci. 61, 569-581.

French-McCay, D., Rowe, J.J., Whittier, N., Sankaranarayanan, S., Etkin, D.S., 2004. Estimation of potential impacts and natural resource damages of oil. J. Hazard. Mater. 107, $11-25$.

Guillen, G., Rainey, G., Morin, M., 2004. A simple rapid approach using coupled multivariate statistical methods, GIS and trajectory models to delineate areas of common oil spill risk. J. Mar. Syst. 45, 221-235.

Gundlach, E.R., Hayes, M.O., 1978. Vulnerability of coastal environments to oil spill impacts. Mar. Technol. Soc. J. 12, 18-27.

Hainbucher, D., Wei, H., Pohlmann, T., Suendermann, J., Feng, S., 2004. Variabilityof the Bohai Sea circulation based on model calculations. J. Mar. Syst. 44, 153-174.

He, Y., Lu, X., Qiu, Z., Zhao, J., 2004. Shallow water tidal constituents in the Bohai Sea and the Yellow Sea from a numerical adjoint model with TOPEX/POSEIDON altimeter data. Cont Shelf Res. 24, 1521-1529.

Hoch, M., 2010. New estimate puts Gulf oil leak at 205 million gallons. http://www.pbs. org/newshour/rundown/new-estimate-puts-oil-leak-at-49-million-barrels/.

HydroQual, 2015. http://www.hydroqual.com/ehst_ecomsed.html.

Jin, M., Wang, J., 2004. Interannual variability and sensitivity study of the ocean circulation and thermohaline structure in Prince William Sound, Alaska. Cont. Shelf Res. $24,393-411$ 
Liang, S.X., Nakatsuji, K., Sun, Z.C., Yamanaka, R., 2003. Residual circulation system and its driving mechanism in the Bohai Sea. In the Proceedings of the International Conference on Estuaries and Coasts, pp. 888-902.

Liu, D., Zhu, L., 2014. Assessing China's legislation on compensation for marine ecological damage: a case study of the Bohai oil spill. Mar. Policy 50, 18-26.

Liu, X., Guo, J., Guo, M., Hu, X., Tang, C., Wang, C., Xing, Q., 2015. Modelling of oil spill trajectory for 2011 Penglai 19-3 coastal drilling field, China. Appl. Math. Model. 39, 5331-5340.

Mao, X., Jiang, W., Zhao, P., Gao, H., 2008. A 3-D numerical study of salinity variations in the Bohai Sea during the recent years. Cont. Shelf Res. 28, 2689-2699.

Mariano, A.J., Kourafalou, V.H., Srinivasan, A., Kang, H., Halliwellb, G.R., Ryan, E.H., Roffer, M., 2011. On the modeling of the 2010 Gulf of Mexico oil spill. Dyn. Atmos. Oceans 52, $322-340$.

Marta-Almeida, M., Ruiz-Villarreal, M., Pereira, J., Otero, P., Cirano, M., Zhang, X., Hetland, R.D., 2013. Efficient tools for marine operational forecast and oil spill tracking. Mar. Pollut. Bull. 71, 139-151.

Michel, J., Henry Jr., C.B., Thumm, S., 2002. Shoreline assessment and environmental impacts from the M/T Westchester Oil Spill in the Mississippi River. Spill Sci. Technol. Bull. 7, 155-161.

Ning, X., Lin, C., Su, J., Liu, C., Hao, Q., Le, F., Tang, Q., 2010. Long-term environmental changes and the responses of the ecosystems in the Bohai Sea during 1960-1996. Deep-Sea Res. II Top. Stud. Oceanogr. 57, 1079-1091.

NOAA, 2010. http://www.ngdc.noaa.gov/mgg/coast/.

Oey, L.Y., Ezer, T., Lee, H.C., 2005. Loop Current, rings and related circulation in the Gulf of Mexico: a review of numerical models and future challenges. In: Sturges, W., LugoFernandez, A. (Eds.), Circulation in the Gulf of Mexico: Observations and Models. Geophys. Monograph Ser. 161, pp. 31-56.
Spaulding, M.L., Kolluru, V.S., Anderson, E., Howlett, E., 1994. Application of three-dimensional oil spill model (WOSM/OILMAP) to Hindcast the Braer spill. Spill Sci. Technol. Bull. 1, 23-35

Su, H., Wang, Y., Xiao, J., Li, L., 2013. Improving MODIS sea ice detectability using gray level co-occurrence matrix texture analysis method: a case study in the Bohai Sea. ISPRS J. Photogramm. Remote Sens. 85, 13-20.

Sündermann, J., Feng, S., 2004. Analysis and modelling of the Bohai sea ecosystem-a joint German-Chinese study. J. Mar. Syst. 44, 127-140.

TELEGRAPH, 2010. BP leak the world's worst accidental oil spill. http://www.telegraph.co. uk/finance/newsbysector/energy/oilandgas/7924009/BP-leak-the-worlds-worstaccidental-oil-spill.html.

Vandermeulen, J.H., Ross, C.W., 1995. Oil spill response in freshwater: assessment of the impact of cleanup as a management tool. J. Environ. Manag. 44, 297-308.

Varlamov, S.M., Yoon, J.H., Hirose, N., Kawamura, H., Shiohara, K., 1999. Simulation of the oil processes in the Sea of Japan Sea with regional ocean circulation model. J. Mar. Sci. Technol. 4, 94-107.

Wang, S.D., Shen, Y.M., Zheng, Y.H., 2005. Two-dimensional numerical simulation for transport and fate of oil spills in seas. Ocean Eng. 32, 1556-1571.

Wang, S.D., Shen, Y.M., Guo, Y.K., Tang, J., 2008. Three-dimensional numerical simulation for transport of oil spills in seas. Ocean Eng. 35, 503-510.

Wei, H., Hainbucher, D., Pohlmann, T., Feng, S., Suendermann, J., 2004. Tidal-induced Lagrangian and Eulerian mean circulation in the Bohai Sea. J. Mar. Syst. 44, 141-151.

Xu, H., Chen, J., Wang, S., Liu, Y., 2012. Oil spill forecast model based on uncertainty analysis: a case study of Dalian oil spill. Ocean Eng. 54, 206-212.

Zhou, H., Zhang, Z.N., Liu, X.S., Tu, L.H., Yu, Z.S., 2007. Changes in the shelf macrobenthic community over large temporal and spatial scales in the Bohai Sea, China. J. Mar Syst. 67, 312-321. 